
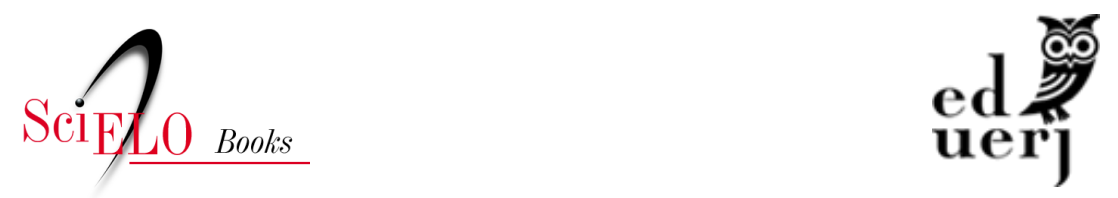

\title{
Introdução - Congresso remoto como investimento
}

\author{
Fabiano Santos
}

\section{SciELO Books / SciELO Livros / SciELO Libros}

SANTOS, F. Introdução - Congresso remoto como investimento. In.: SANTOS, F., ed. Congresso remoto: a experiência legislativa brasileira em tempos de pandemia [online]. Rio de Janeiro, 2021, pp. 13-20. Sociedade e política collection. ISBN:

978-65-88808-12-2. https://doi.org/10.7476/9786588808122.0002.

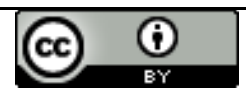

All the contents of this work, except where otherwise noted, is licensed under a Creative Commons Attribution 4.0 International license.

Todo o conteúdo deste trabalho, exceto quando houver ressalva, é publicado sob a licença Creative Commons Atribição 4.0.

Todo el contenido de esta obra, excepto donde se indique lo contrario, está bajo licencia de la licencia Creative Commons Reconocimento 4.0. 


\section{INTRODUÇ̃̃O \\ CONGRESSO REMOTO COMO INVESTIMENTO}

Fabiano Santos

A democracia brasileira agora passa por sua pior crise desde o advento da Nova República nos anos 1980. Crise de legitimidade profundamente ligada à percepção generalizada de falta de responsabilização e capacidade de resposta dos representantes eleitos perante o eleitorado. Tal situação tornou-se ainda mais grave sob o governo de Jair Bolsonaro, e ao longo do ano de 2020, quando o Executivo passou a desafiar publicamente o Congresso Nacional, inclusive por meio do apelo a manifestações de rua. Infelizmente, a crise da democracia representativa não é exclusiva do Brasil. Pelo contrário, com raras exceções, os governos democráticos estão sob estresse por razões muito semelhantes em todo o mundo, isto é, não apenas na América Latina ou no Sul Global, mas também nos chamados países desenvolvidos, como os Estados Unidos e os europeus.

Desde o restabelecimento da democracia em meados dos anos 1980, o Congresso viu crescer sua importância como espaço de debate e formulação de políticas públicas em razão de seu renovado papel na produção legislativa do país. Nesse período, o Brasil fortaleceu sua estrutura de governança sobre temas ligados à cidadania, meio ambiente, direitos humanos e de minorias, estrutura apoiada invariavelmente em leis inovadoras, aprovadas por iniciativa de representantes com assento na Câmara dos Deputados ou 
no Senado Federal. A eleição de Bolsonaro, entretanto, levou ao Planalto e, por conseguinte, ao Legislativo federal, uma agenda de retrocessos. O resultado de 2018 surge no esteio de importantes transformações na política brasileira, que puseram em xeque partidos e agendas em torno dos quais uma pauta mais progressista, mesmo que com muitas dificuldades, pôde avançar desde 1988. E é nesse novo cenário que o Congresso apresenta papel revigorado, como importante espaço de ação política frente a um Executivo hostil, fechado às demandas da sociedade civil.

O Congresso Nacional é, por definição, representativo e aberto à influência da sociedade civil, sendo, portanto, um espaço em que a formulação de políticas deve assumir caráter público e transparente, quando comparado ao Executivo. Por essa razão, o Legislativo consiste em importante lócus para a incidência democrática das organizações da sociedade no intuito de influenciar suas decisões. Há hoje, todavia, obstáculos significativos que limitam a abertura dos trabalhos do Legislativo à sociedade civil. Tome-se a notória desigualdade entre a capacidade de incidência de organizações da sociedade civil e a de grandes corporações econômicas, o que desvirtua a vocação republicana do Congresso e limita a expansão da agenda das organizações na legislação nacional. Além disso, temos assistido à desestruturação do sistema político brasileiro nos últimos anos, que aumentou o desconhecimento a respeito do modus operandi das principais forças no Congresso, dificultando, assim, uma ação efetiva de incidência parlamentar.

Sem sombra de dúvida, contudo, o mais importante dos obstáculos, ainda que de natureza conjuntural, consiste na crise sanitária decorrente do surto da Covid-19. O dia 13 de março deste ano marcou o início do afastamento social no Brasil, com a decorrente necessidade de interrupção das atividades presenciais no Legislativo. Quatro dias depois, no dia 17, a Câmara dos Deputados e o Senado Federal publicam, respectivamente, a Resolução no 14/2020 e o Ato da Mesa n. 07, instituindo cada um o Sistema de Deliberação 
Remota (SDR). O SDR foi criado para viabilizar o funcionamento das Casas legislativas durante a crise sanitária e econômica causada pela pandemia, permitindo a discussão e votação de matérias, preferencialmente voltadas à emergência de saúde pública, sujeitas à apreciação do plenário de forma remota. $\mathrm{O}$ estudo desta curta e riquíssima experiência é o objetivo do volume que se segue.

A experiência traz resultados acadêmicos tão relevantes quanto óbvios. Com a decisão de Bolsonaro de não montar coalizão formal com os grandes partidos representados no Legislativo, já se esperava que as potencialidades de autonomização das atividades da Câmara e do Senado recebessem novo impulso. Com a adoção do SDR, a crise sanitária e o negacionismo adotado pelo presidente e seu círculo mais próximo, tais potencialidades apenas se acentuaram. Descrever e narrar tal processo é um dos objetivos centrais do volume. Veremos que, devido às contribuições mais importantes e recentes na literatura sobre o envolvimento do Congresso em políticas públicas no bojo do presidencialismo de coalizão, tais como em Freitas (2016) e em Meirelles (2019), a tese da independência decisória do Legislativo, presente em Almeida (2018) ganha força, em particular, por conta de sua crescente capacidade de gerar e circular informação qualificada em torno das matérias sob escrutínio.

A autonomia decisória, contudo, não é apenas resultado do aumento contínuo da expertise em políticas públicas, expertise acumulada nas comissões temáticas e nas assessorias. É também fruto da presença de organizaçóes de relações governamentais e advocacy no interior do processo decisório do Legislativo. Como manter tal presença foi um dos grandes desafios colocados pelo Congresso Remoto, desafio que transcendeu o canteiro central da asa leste do Eixo Monumental ao penetrar na ideia mesma de institucionalidade democrática do sistema político em seu conjunto. Nesse sentido específico, o SDR foi uma boa surpresa. Contar ao público mais amplo o porquê e como foi uma boa surpresa é o segundo e mais fundamental objetivo do livro. 


\section{Estrutura do volume}

O capítulo 1 do presente volume oferece uma narrativa sobre o momento político no qual se instala a crise sanitária da Covid-19 e como o Legislativo assume a ponta de lança no processo de tomada de decisão em políticas relacionadas à crise, protagonismo que se viabiliza por meio das atividades legislativas em modo remoto. $\mathrm{O}$ objetivo de Fabiano Santos e Cristiane Batista foi explicitamente descritivo e não explicativo. Apoiado na hipótese de ter havido uma evolução institucional envolvendo o Legislativo brasileiro no sentido de torná-lo mais proativo no processo decisório em políticas públicas, os autores utilizam o contexto da pandemia para revelar ao mesmo tempo que tal evolução institucional encontra-se associada ao investimento de mais longo prazo em assessoria e informação. Em suma, a crônica da reação de deputadas, deputados, senadoras e senadores e o novo ambiente político gerado pela crise sanitária fornece material rico para futuras pesquisas sobre as instituições democráticas no Brasil.

O capítulo 2, de Fabiano Santos e Debora Gershon, expõe de forma sucinta as alterações introduzidas no processo legislativo federal brasileiro, na Câmara dos Deputados, no Senado Federal e no Congresso Nacional (este na tramitação de medidas provisórias), uma vez decretada a emergência sanitária em todo o território nacional, decorrente da pandemia da Covid-19 e a suspensão das atividades normais do Poder Legislativo. Examina, ao mesmo tempo, os efeitos mais importantes de tais alterações tendo em vista a transparência das decisões do sistema político nessa situação de crise sanitária, econômica e política. A análise revela como o país acabou se deparando com o problema de assegurar o funcionamento das instituições democráticas, dado que o encontro presencial de parlamentares se tornara inviável, mostrando que o Legislativo agiu de maneira surpreendentemente rápida por meio de sua estrutura de Tecnologia da Informação e criação do Sistema de Deliberação 
Remota (SDR). Contudo, o movimento patrocinado pelo Congresso tornou-se rapidamente objeto de preocupação das organizações da sociedade civil. Em cartas enviadas ao Supremo Tribunal Federal e aos presidentes da Câmara e do Senado, dezenas de entidades pedem atenção e intervenção quanto às possibilidades de haver atropelo de direitos e procedimentos democráticos básicos, por conta da óbvia restrição no tempo e condições de debate das proposições colocadas para decisão em plenário.

O capítulo 3 examina informações sobre o comportamento de deputadas e deputados no plenário virtual da Câmara, comparando o período da pandemia com o que ocorreu em anos anteriores. Fabiano Santos, Júlio Canello e Leonardo Barbosa direcionam o foco para o padrão de apoio recebido pelo governo em votações nominais, ao analisar a estrutura do conflito político na "Casa baixa" e como a crise causada pela pandemia impactou essa estrutura. Resultados panorâmicos sobre as votações (nominais e simbólicas) na Câmara dos Deputados são expostos e descritos, bem como o grau de consenso obtido nas votaçóes nominais. Projeta-se, tendo em vista a aproximação formal de partidos do chamado "centrão" à base de apoio do governo, um futuro próximo da estabilidade, embora nenhuma previsão seja feita quanto à sustentabilidade do arranjo montado pelo Executivo - dados os diversos fatores, externos e conjunturais, potencialmente causadores de novas crises.

O capítulo 4 traz a mesma análise só que com os olhos voltados para Senado Federal. Júlio Canello, Debora Gershon e Leonardo Barbosa mostram como o Sistema de Deliberação Remota (SDR) mudou a dinâmica de funcionamento da Casa, com impacto sobre temas abordados, regras do processo decisório e organização das forças partidárias nesta Casa. Desde o início da legislatura até o fim de agosto de 2020, o Senado Federal decidiu sobre 650 matérias, entre medidas provisórias, projetos de lei, projetos de lei complementar, propostas de emenda à Constituição, além de substitutivos e emendas da Câmara dos Deputados. Ao se comparar o 
comportamento neste período de funcionamento excepcional com o período pré-pandemia nota-se que senadoras e senadores priorizaram o debate sobre a crise da Covid-19, em coordenação com a Câmara, reduzindo de forma significativa o grau de aderência às propostas e posições governamentais.

No capítulo 5, Debora Gershon e Leonardo Barbosa apresentam um quadro geral sobre a agenda considerada prioritária no Congresso de meados de março até início de julho, período auge de vigência do Sistema de Deliberação Remota (SDR). O requerimento de urgência tornou-se peça-chave na dinâmica de votação de proposições legislativas no plenário das Casas, uma vez que o funcionamento das Comissões foi suspenso. O texto descreve sinteticamente as mudanças implantadas pelo SDR, no que diz respeito à atribuição do status de urgência a determinadas matérias, tanto na Câmara quanto no Senado, e sistematiza a produção do Congresso em tramitação sob a égide do SDR, para, por fim, mostrar que de fato a agenda legislativa seguiu as diretrizes constantes dos documentos que embasaram a adoção do SDR.

No capítulo 6, Vitor Oliveira avalia a atuação da sociedade civil em tempos de pandemia por meio da conceituação de suas ações no âmbito da política institucional. Além disso, descreve e examina dois casos emblemáticos de ação coletiva de movimentos de advocacy, no sentido de influenciar políticas públicas em tramitação no nível nacional. O texto explora o modo pelo qual as organizações e suas lideranças resolveram problemas de coordenação e mobilização no plano federal, em um cenário de escassez das ferramentas tradicionais de lobbying. Duas variáveis aparecem como chaves: o senso de oportunidade dos atores, com o aproveitamento das janelas abertas pelo processo legislativo; e o capital político construído ao longo de anos pelas organizações, potencializados por estratégias de comunicação e mobilização virtuais. Enfim, o autor expõe como foi relevante a sinalização da amplitude ideológica das coalizões formadas nos dois momentos em tela, por meio da estratégia de 
diversidade na seleção de porta-vozes, bem como de mobilização massiva, em escala poucas vezes vista fora de períodos eleitorais ou de impeachment.

O capítulo 7, de João Feres Júnior, coloca a iniciativa no Congresso Remoto em perspectiva histórica de longa duração, ao tomá-lo como pertencente à classe de medidas adotadas em contextos republicanos para se debelar os efeitos de crises sociais e política agudas. Para tal, o autor examina o significado histórico do conceito de crise, mostrando como ele sempre esteve ligado à demanda por uma solução ou decisão. Em seguida, são examinadas as soluções preconizadas pela tradição do pensamento político e pelas instituições, desde a antiguidade clássica até os dias de hoje. A resposta dessa tradição é a adoção de interregnos autocráticos cuja finalidade é debelar a crise e restaurar a ordem anterior. O problema é que tal resposta historicamente se confundiu com usurpações autocráticas da República. $\mathrm{O}$ autor conclui mostrando como a instituição do Congresso Remoto, ao possibilitar a continuidade do funcionamento legislativo de maneira extremamente temporânea, fechou a janela para soluções autocráticas para essa crise de enormes proporções, preservando assim o funcionamento da democracia brasileira.

Por fim, o capítulo de San Romanelli Assumpção, como o próprio título anuncia, tece considerações normativas acerca do Congresso Remoto. Aqui a perspectiva não é histórica, mas puramente teórica. Para além do âmbito da saúde pública, ou mesmo misturado a ele, a autora mostra como a crise da Covid-19 é ao mesmo tempo social, Estatal e política. Seu caráter social é óbvio pelos imensos distúrbios que incidem diretamente sobre a vida das pessoas, seja no âmbito laboral, familiar, pessoal e de convívio. $\mathrm{O}$ caráter Estatal da crise é muito importante de ser compreendido, pois perante ela não há espaço neutro, ou o Estado intervém com o intuito de debelar suas consequências, e isso requer um enorme esforço e capacidade, ou ele se omite e permite que a pandemia tenha seu poder destrutivo maximizado. O problema é que quando o ramo 
administrativo do Estado, o Executivo, é comandado por um grupo político negacionista e incompetente, como é o caso atual, a questão Estatal se traduz rapidamente em profunda crise política. Ao instituir o Congresso Remoto, evitando ao mesmo tempo soluções autoritárias e omissão estatal, o Poder Legislativo tenta debelar ou pelo menos lidar com a crise política de maneira a permitir soluções para as crises Estatal e social trazidas pela pandemia. Tal ato afirma o primado da política e da democracia.

\section{Referências}

Almeida, Acir. Governo Presidencial Condicionado: delegação e participação legislativa na Câmara dos Deputados. (Tese). Universidade do Estado do Rio de Janeiro (IESP-UERJ), Rio de Janeiro, 2018.

Freitas, Andréa. O Presidencialismo da Coalizão. Rio de Janeiro: Konrad Adenauer Stiftung, 2016.

Meirelles, Fernando. A Política Distributiva da Coalizão. (Tese). Universidade Federal de Minas Gerais, Minas Gerais, 2019. 